\title{
Leader
}

\section{The molecular basis of disorders of the red cell membrane}

\author{
Mary F McMullin
}

Haemolytic anaemia denotes a state in which there is an increased rate of red cell destruction. It can be classified on the basis of whether the defect is intrinsic to the red cell or extrinsic to the red cell (that is, a problem in the surrounding environment). Intrinsic defects include defects in the red cell membrane, defects in the red cell enzymes, and defects in globin structure and synthesis. They are generally congenital although there are a few rare acquired intrinsic erythrocyte defects (for a full discussion of the causes of haemolytic anaemia, see Lee et al, 1993 ${ }^{1}$ ).

In this review I shall provide an overview of the molecular basis of the intrinsic defects of the red cell membrane. Although the majority of red cell membrane defects are congenital, we now have considerable knowledge of some acquired intrinsic red cell defects such as paroxysmal nocturnal haemoglobinuria which I shall also discuss.

\section{The red cell membrane}

The red cell membrane consists of a lipid bilayer which contains 95\% cholesterol and phospholipids. It is studded with proteins which are involved in transport or signalling. The inner surface of the bilayer is a lattice of proteins which make up the membrane skeleton or red cell skeleton (fig 1). Skeletal proteins include spectrin $\alpha$ and $\beta$ chains which form dimers and tetramers. These are linked horizontally to actin and protein 4.1. There are many additional proteins including adducin and dematin. Vertically the skeleton is linked to the bilayer. The anion exchanger (AE1) is a transporter protein which is connected via ankyrin to spectrin. Protein 4.2 interacts with AE1. Protein 4.1, protein p55, and glycophorins $C$ and D are attached vertically. The outer surface of the bilayer has a number of linked components including the glycosylphosphatidylinositol (GPI) anchored proteins. The
Department of Haematology, The Queen's University of Belfast, Institute of Clinical Science, Royal Victoria Hospital, Grosvenor Road, Belfast BT12 6BA, UK M F McMullin

Correspondence to: Dr McMullin email:

M.McMullin@qub.ac.uk

Accepted for publication 23 October 1998

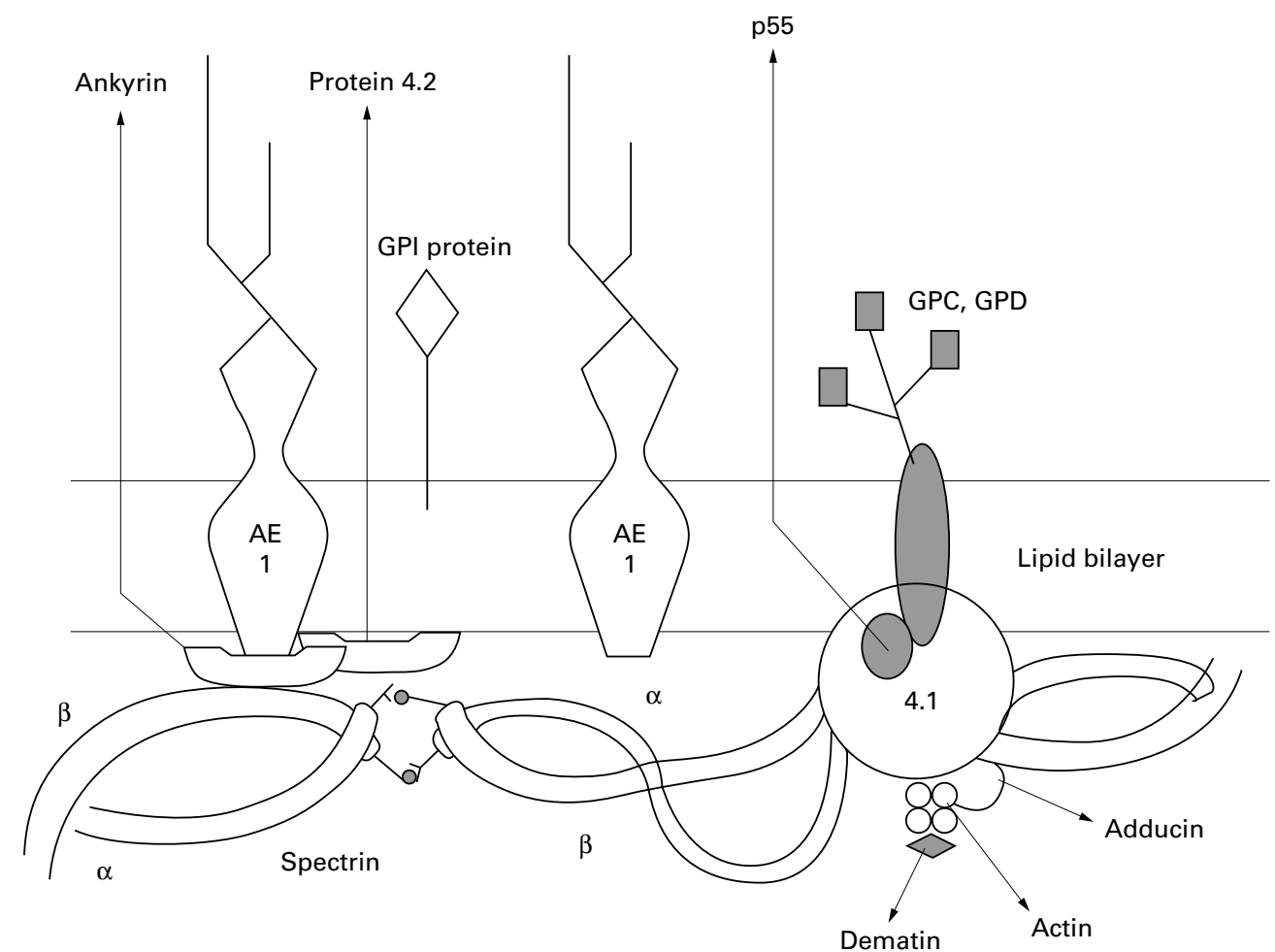

Figure 1 (After Delaunay ${ }^{2}$ ) Diagram of the red cell membrane and skeleton. AE1, anion exchanger; GPI protein, glycosylphosphatidylinositol anchored protein; GPC, glycophorin $C ; G P D$, glycophorin $D$. 
membrane and the skeleton are the chief determinants of erythrocyte mechanical properties. ${ }^{2}$

\section{Hereditary spherocytosis}

Hereditary spherocytosis is a congenital haemolytic anaemia characterised by a reduction in red cell osmotic resistance. The inheritance can be autosomal dominant or recessive. Affected cases are often compound heterozygotes. Microscopically it is associated with the presence of spherocytic red cells. The disease phenotype is represented by a variety of different genetic lesions. ${ }^{34}$

ANYKRIN GENE ABNORMALITIES

The anykrin gene is located at $8 \mathrm{p} 11.2$ and contains 42 exons. The protein is produced in various forms due to alternative splicing of the mRNA. It has chymotrypic domains and binds to AE1, spectrin, and protein 4.2 . Some $70 \%$ of cases of hereditary spherocytosis are associated with anykrin mutations, $20 \%$ of which arise de novo. Many of these mutations are private to the affected kindred. Dominant inheritance patterns include mutations that lead to an absence of one haploid set of anykrin or to the truncation of the molecule. Other mutations lead to amino acid substitutions.

ANION EXCHANGER GENE ABNORMALITIES

$\mathrm{AE} 1$ is also known as band 3. The gene maps to $17 q 21-q t e r$ and contains 20 exons. It has cytoplasmic and transmembrane areas and binds to anykrin, protein 4.1 , and protein 4.2. Approximately $25 \%$ of cases of hereditary spherocytosis are associated with a $20 \%$ to $40 \%$ reduction of the AE1.

The inheritance pattern is autosomal dominant. The responsible mutations are either stop codons leading to the failure of synthesis of one AE1 haploid, or mutations that prevent AEI being conveyed to, or inserted into, the membrane. All the described changes affect the membrane portion of AE1. Mutations have been described which specifically affect the binding site of AE1 and protein 4.2.

PROTEIN 4.2 GENE ABNORMALITIES

This gene maps to $15 \mathrm{q} 15$ and has 13 exons. There is a rare subset of rather homogeneous clinical presentations with a protein 4.2 abnormality. The disorder has an autosomal recessive pattern of inheritance. They are usually single amino acid substitutions.

SPECTRIN GENE ABNORMALITIES

The spectrin $\alpha$ and $\beta$ genes map to $1 \mathrm{q} 22-\mathrm{q} 23$ and $14 \mathrm{q} 23-\mathrm{q} 24.2$. Compound heterozygotes for spectrin $\alpha$ gene mutations have been described in autosomal recessive hereditary spherocytosis. A few mutations of the spectrin $\beta$ chain have been found to be responsible for heterozygotes of hereditary spherocytosis in man.

\section{Hereditary elliptocytosis}

Hereditary elliptocytosis is diagnosed by the appearance of the characteristic elliptocytes microscopically. More severe forms, which are often referred to as hereditary pyropoikilocytosis, have more bizarre morphology. Inheritance can be autosomal dominant or recessive.

SPECTRIN

The spectrin $\alpha$ and $\beta$ genes contain 52 and 32 exons, respectively. These each code for a chain which consists of a series of repeats of about 106 amino acids $\alpha 1-\alpha 22$ and $\beta 1-\beta 17$. Dimerisation is initiated at two nucleation sites, $\alpha 19-\alpha 22$ and $\beta 1-\beta 5$. Two dimers self associate head to head through the $\mathrm{N}$ terminal of the $\alpha$ chain $\alpha 1$ and the $C$ terminal of the $\beta$ chain $\beta 17 .^{56}$

SPECTRIN $\alpha$ GENE ABNORMALITIES

At least 20 mutations have been described in hereditary elliptocytosis in the spectrin $\alpha$ gene (referred to as $\alpha^{\mathrm{HE}}$ ). These all occur round the site which codes for the self association site of the spectrin dimer and the more remote mutations from this site have less effect on self association. ${ }^{7}$ States where there is low expression of the spectrin $\alpha$ gene (referred to as $\alpha^{\text {LELY }}$ allele) have also been described. The allele has two mutations at position 1857 (CTA $\rightarrow$ GTA: Leu $\rightarrow$ Val; nt 7 of exon 40) and at position -12 of intron $45(\mathrm{C} \rightarrow \mathrm{T})$, the second of which probably leads to skipping of exon 46. This allele is very common, being present in $20-30 \%$ of Europeans, Africans, Chinese, and Japanese. If $\alpha^{\mathrm{HE}}$ mutations of $\alpha$ spectrin occur with the low expression allele assembly of $\alpha^{\mathrm{HE}} / \beta$ dimers is generally favoured. Such dimers cannot self associate and haemolysis results.

SPECTRIN $\beta$ GENE ABNORMALITIES

Mutations of the spectrin $\beta$ gene causing hereditary elliptocytosis occur at the self association site, the $\mathrm{C}$ terminal site. Point mutations cause normal expression in the heterozygous state but severe disease in homozygotes.

PROTEIN 4.1 GENE ABNORMALITIES

Absence or reduction in the protein occurs in heterozygotes and homozygotes. Owing to the length and complexity of the protein 4.1 gene, only a few mutations which cause protein 4.1 reduction have been described and many alleles are likely to be private alleles. Some individuals have also been described who have abnormal protein 4.1 leading to hereditary elliptocytosis.

GLYCOPHORIN C

The glycophorin C (GPC) gene is located at 2q14-q21. Some individuals who have absent GPC have hereditary elliptocytosis. These people have reduced protein 4.1 as a secondary phenomenon.

\section{Southeast Asian ovalocytosis}

This autosomal dominant disease is characterised by the presence of typical ovalocytes in the peripheral blood film. It is found in individuals from areas including Malaysia, Papua New Guinea, and the Philippines. The heterozygote is asymptotic but the homozygous form is presumed to be lethal in utero. ${ }^{8}$ The molecular 
defect is a deletion of nine codons in the anion exchanger gene (band 3 ) occurring with a point mutation, "the Memphis polymorphism," in cis of the deletion. ${ }^{9}{ }^{10}$ The AE1 is important for maintaining the red cell internal milieu by passive anion transport and maintaining shape through attachment of ankyrin and spectrin. ${ }^{11}$ The mutation leads to deficient anion transport, increased tendency for AE1 to form tetrameters, and red cell rigidity. Heterozygotes may have red cells which are more likely to be destroyed by the reticuloendothelial system if infected by malaria. ${ }^{12}$

\section{Hereditary stomatocytosis}

This group of hereditary haemolytic anaemias has defects which lead to abnormal permeability of the red cell membrane to the cations $\mathrm{Na}^{+}$ and $\mathrm{K}^{+}$. Some of the cases show the classical stomatocytes on morphological examination. The molecular events leading to the abnormality have not been identified, although extensive biochemical characterisation has been carried out. ${ }^{13}$

\section{Paroxysmal nocturnal \\ haemoglobinuria-an acquired red cell membrane disorder}

Paroxysmal nocturnal haemoglobinuria $(\mathrm{PNH})$ is an acquired disorder where the clonal nature has been shown by classic G6PD heterozygosity studies. ${ }^{14}$ Clinically it is characterised by intravascular haemolysis, aplastic anaemia, and venous thrombosis. ${ }^{15}$ There are several proteins missing from $\mathrm{PNH}$ blood cells including delay accelerating factor (CD55), membrane inhibitor of reactive lysis (CD59), alkaline phosphatase, and acetylcholinesterase. The missing proteins are functionally diverse but they are all linked to the cell membrane by the glycosylphosphatidylinositol (GPI) anchor (fig 2). A gene has been described which complements the abnormal expression of the GPI anchor in a PNH cell line. This gene PIG-A (phosphatidylinositol glycan class A) encodes a protein that is essential for normal synthesis of an early intermediate of the pathway of GPI anchor assembly. The gene has been localised on the short arm of the $\mathrm{X}$ chromosome (Xp22.1) and has six exons. ${ }^{16}{ }^{17}$

At least 98 somatic mutations of this gene have been described. The majority are deletions or insertions, the most common consequence of which is a frameshift and thus a premature stop codon. Point mutations occur causing missense mutations, nonsense mutations, and splice site mutations. There are no described mutations of the promoter or $3^{\prime}$ enhancer regions. A single polymorphism has been described in the wild type gene. Most mutations are unique to the patient and mutations are distributed throughout the gene, suggesting there is not a mutation "hot spot" in the gene. Multiple clones have been detected in some patients, giving rise to separate populations of cells in the same patient. These mutations are always somatic, suggesting that a germ line defect would be incompatible with life. As the gene is on the $\mathrm{X}$ chromosome and the other X chromosome is "lyonised" in females, leading to inactivation of the lyonised

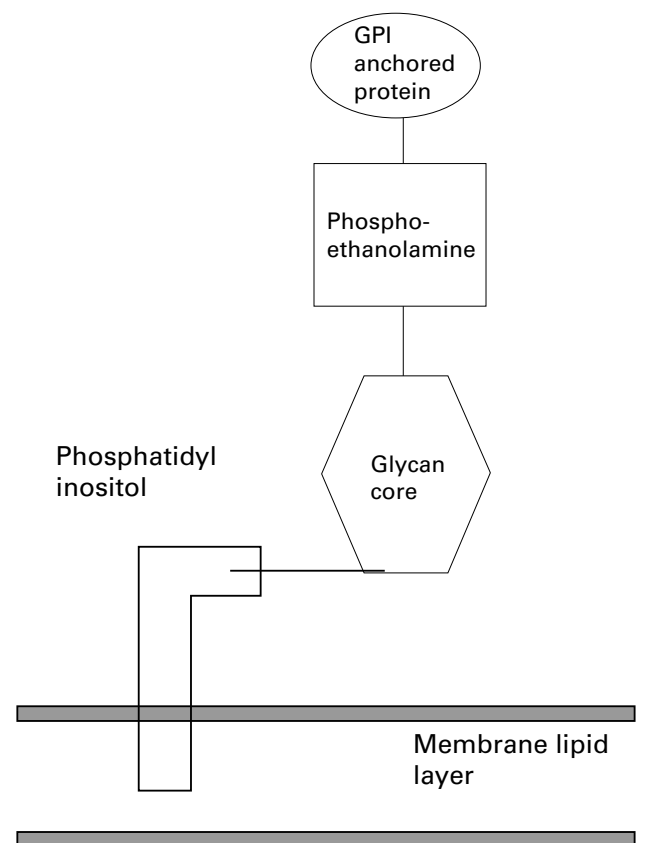

Figure 2 Schematic representation of the glycosylphosphatidylinositol (GPI) anchor. Protein is linked through a phosphoethanolamine group and a glycan core to a phosphatidylinositol group which has a variable fatty acid side chain.

gene. Damage to a single gene results in abnormal GPI anchor expression. ${ }^{18}$ The lack of GPI linked proteins CD55 and CD59 in PNH patients means that the red cells are sensitive to the haemolytic action of complement and haemolysis results. Thus the molecular lesion in PIG-A explains the acquired haemolytic anaemia but it does not account for all the features of PNH. ${ }^{19-21}$

\section{Conclusion}

The examination of the molecular basis of red cell membrane disorders has given us insight into the disease mechanisms. In some cases (hereditary spherocytosis and hereditary elliptocytosis) identification of the molecular defect has become nearly routine whereas in other disorders we still have no clear understanding of the molecular basis of the disease. Elucidation of the molecular basis of the acquired disorder PNH has greatly enhanced our understanding of disease process but still leaves many unanswered questions.

1 Lee GR, Bithell TC, Foerster J, et al. Wintrobe's clinical hematology, 9th ed. Philadelphia: Lea and Febiger, 1993:944-64

2 Delaunay J. Genetic disorders of the red cell membrane. Crit Rev Oncol Hematol 1995;19:79-110.

3 Delaunay J. Genetic disorders of the red cell membranes. FEBS Lett 1995;369:34-7.

4 Hassoun H, Palek J. Hereditary spherocytosis: a review of the clinical and molecular aspects of the disease. Blood Rev 1996;10:129-47.

5 Delaunay J, Allosio N, Morle L, et al. Molecular genetics of hereditary elliptocytosis and hereditary spherocytosis. Ann Genet 1996;39:209-21.

6 Gallagher PG, Forget BG. Hematologically important mutations: Spectrin variants in hereditary elliptocytosis and hereditary pyropoikilocytosis. Blood Cells $\mathrm{Mol}$ Dis 1996;22:254-8

7 Gallagher PG, Kotula L, Wang Y, et al. Molecular basis and haplotyping of the $\alpha 11$ domain polymorphisms of spectrin: application to the study of hereditary elliptosis and application to the study of hereditary elliptosi

8 Mgone CS, Koki G, Paniu MM, et al. Occurrence of the erythrocyte band 3 (AEI) gene deletion in relation to malaria endemicity in Papua New Guinea. Trans $R$ Soc Trop Med Hyg 1996;90:228-31. 
9 Jarolim P, Palek J, Amato D, et al. Deletion in erythrocyte band 3 gene in malaria-resistant Southeast Asian ovalocyband 3 gene in malaria-resistant Southeast Asia
tosis. Proc Natl Acad Sci USA 1991;88:11022-6.

10 Bruce LJ, Tanner MJA. Structure-function relationships of band 3 variants. Cell Mol Biol 1996;42:953-73.

11 Jay DG. Role of band 3 in homeostasis and cell shape. Cell 1996;86:853-4.

12 O'Donnell A, Allen SJ, Mgone CS, et al. Red cell morphology and malaria anaemia in children with Southeast-Asian ovalocytosis band 3 in Papua New Guinea. Br $\mathcal{F}$ Haemato 1998;101:407-12.

13 Stewart GW. The membrane defect in hereditary stomatocytosis Clin Haematol 1993;6:371-99.

14 Oni SB, Osunkoya BO, Luzzatto L. Paroxysmal nocturnal hemoglobinuria: evidence for monoclonal origin of abnormal red cells. Blood 1970;36:145-52.

15 Hillmen P, Lewis SM, Bessler M, et al. Natural history of paroxysmal nocturnal hemoglobinuria. $N$ Engl $\mathcal{f} \mathrm{Med}$ 995;333:1253-8.

16 Rosse WR Paroxysmal nocturnal hemoglobinuria as a molecular disease. Rev Mol Med 1997;76:63-93.

17 Devetten MP, Liu JM, Ling V, et al. Paroxysmal nocturnal hemoglobinuria: new insights from murine pig a-deficient hematopoiesis. Proc Assoc Am Physicians 1997;109:99-110

8 Rosse WR, Ware RE. The molecular basis of paroxysmal nocturnal hemoglobinuria. Blood 1995;86:3277-86.

19 Nakakuma H. Mechanism of intravascular hemolysis in paroxysmal nocturnal hemoglobinuria (PNH). Am $\mathcal{F}$ Hematol 1996;53:22-9.

20 Parker CJ. Molecular basis of paroxysmal nocturnal hemoglobinuria. Stem cells 1996;14:396-411.

21 Bessler M. Paroxysmal nocturnal hemoglobinuria: the price for a chance. Schweiz Med Wochenschr 1996;126: 1912-21.

\section{The Royal College of Pathologists "The Best" of the College Symposia}

Academic activities, Continuing Professional Development, and Blackwell Healcare Communications are publishing a CD-ROM containing highlights of past College Symposia.

This CD-ROM is approved for CPD credits and is of general interest to pathologists. It covers a wide range of topical issues, with lectures entitled:

- Allergy and asthma

- Peanut allergy

- A practical approach to unexpected infant death

- Vitamin K prophylaxis: can we ever reach a consensus?

- Epidemiology of adverse effects of "designer drugs"

- Multi-drug resistance modifiers: an alternative approach

- Idiopathic myelofibrosis: pathogenesis to treatment

- Adhesion molecules in pathology

- Chromosomal changes and cancer

- Interpretation of injury in road traffic accidents

- Reporting of cervical biopsies in the context of the cervical screening programmes

- The metastatic process: its biological basis

- Human papilloma virus infection

- The hepatitis virus

- Alcoholic liver disease

The CD-ROM will cost you $£ 30$ for a personal copy or $£ 120$ for an institutional copy with multiple user licence. To order a copy, call 01719305862. 